\title{
Sugarcane bagasse pretreatment using three imidazolium-based ionic liquids; mass balances and enzyme kinetics
}

\author{
Sergios Kimon Karatzos ${ }^{1}$, Leslie Alan Edye ${ }^{1 *}$ and William Orlando Sinclair Doherty ${ }^{2}$
}

\begin{abstract}
Background: Effective pretreatment is key to achieving high enzymatic saccharification efficiency in processing lignocellulosic biomass to fermentable sugars, biofuels and value-added products. lonic liquids (ILs), still relatively new class of solvents, are attractive for biomass pretreatment because some demonstrate the rare ability to dissolve all components of lignocellulosic biomass including highly ordered (crystalline) cellulose. In the present study, three ILS, 1-butyl-3-methylimidazolium chloride ([C4mim]Cl), 1-ethyl-3-methylimidazolium chloride ([C2mim]Cl), 1-ethyl-3methylimidazolium acetate ([C2mim]OAc) are used to dissolve/pretreat and fractionate sugarcane bagasse. In these IL-based pretreatments the biomass is completely or partially dissolved in ILs at temperatures greater than $130^{\circ} \mathrm{C}$ and then precipitated by the addition of an antisolvent to the IL biomass mixture. For the first time mass balances of IL-based pretreatments are reported. Such mass balances, along with kinetics data, can be used in process modelling and design.

Results: Lignin removals of 10\% mass of lignin in bagasse with [C4mim]Cl, 50\% mass with [C2mim]Cl and 60\% mass with [C2mim]OAc, are achieved by limiting the amount of water added as antisolvent to 0.5 water:L mass ratio thus minimising lignin precipitation. Enzyme saccharification ( $24 \mathrm{~h}, 15 \mathrm{FPU})$ yields (\% cellulose mass in starting bagasse) from the recovered solids rank as: $[\mathrm{C} 2 \mathrm{mim}] \mathrm{OAc}(83 \%)>>[\mathrm{C} 2 \mathrm{mim}] \mathrm{Cl}(53 \%)=[\mathrm{C} 4 \mathrm{mim}] \mathrm{Cl}(53 \%)$. Composition of [C2mim]OAc-treated solids such as low lignin, low acetyl group content and preservation of arabinosyl groups are characteristic of aqueous alkali pretreatments while those of chloride IL-treated solids resemble aqueous acid pretreatments. All ILs are fully recovered after use (100\% mass as determined by ion chromatography).

Conclusions: In all three ILs regulated addition of water as an antisolvent effected a polysaccharide enriched precipitate since some of the lignin remained dissolved in the aqueous IL solution. Of the three IL studied [C2mim] OAc gave the best saccharification yield, material recovery and delignification. The effects of [C2mim]OAc pretreatment resemble those of aqueous alkali pretreatments while those of $[\mathrm{C} 2 \mathrm{mim}] \mathrm{Cl}$ and $[\mathrm{C} 4 \mathrm{mim}] \mathrm{Cl}$ resemble aqueous acid pretreatments. The use of imidazolium IL solvents with shorter alkyl chains results in accelerated dissolution, pretreatment and degradation.
\end{abstract}

Keywords: Ionic liquids, Pretreatment, Sugarcane bagasse, Enzyme hydrolysis

\footnotetext{
* Correspondence: l.edye@qut.edu.au

${ }^{1}$ School of Chemistry, Queensland University of Technology, GPO Box 2434, Brisbane, QLD 4001, Australia

Full list of author information is available at the end of the article
} 


\section{Background}

Lignocellulosics, whether in the form of dedicated energy crops such as switchgrass, agricultural residues such as sugarcane bagasse, or from forestry residues, present an abundant renewable energy resource. With world energy demand predicted to increase in the near future [1], and fossil fuel reserves being depleted and non-renewable, biomass resources have drawn much attention as renewable and sustainable feedstocks for alternative fuels and chemicals.

The conversion of the lignocellulosic biomass polysaccharides to ethanol fuel and/or other products of fermentation (e.g. butanol) involves hydrolysis, fermentation and product separation. However, these polysaccharide molecules are not readily hydrolysed since they are contained in the chemically recalcitrant and structurally complex lignocellulosic matrix. This matrix is designed by nature to protect the plant organism from chemical and biological attack. Therefore, a pretreatment step is added to the process prior to hydrolysis in order to improve saccharification of the polysaccharides.

Most pretreatment technologies are either physical (e.g., size comminution, steam explosion and hydrothermolysis) or chemical, utilizing organic solvents, acids or alkalis [2-4]. These chemical pretreatment technologies occur by either acid or alkali mechanisms at high temperatures and pressures. Acid pretreatments are known to dissolve hemicellulose and cleave arabinosyl glycosidic linkages whereas alkali pretreatments dissolve lignin and cleave acetyl bonds [5].

Recently, ionic liquids (ILs) have drawn a great deal of attention as solvents for pretreatment of lignocellulosics. ILs are a class of organic salts that are liquid at temperatures below $100^{\circ} \mathrm{C}$. Many ILs are non-volatile, nonexplosive, stable at a wide range of temperatures and reaction-condition severities and compatible with a wide array of organic and inorganic functional chemicals and solvents [6]. Pretreatment of the lignocellulosic matrix with ionic liquids occurs by the dissolution-thenprecipitation of solids which exhibit reduced crystallinity and improved enzyme saccharification of cellulose [7-11]. For a thorough review which focuses on dissolution of biomass, lists 74 ILs that have been tested for the ability to dissolve cellulose, wood, pulp, hemicellulose and lignin and also includes other solvents of relevance to woody biomass processing, viz., choline urea mixture - a deep eutectic salt, and $\mathrm{N}$-methylmorpholine-N-oxide monohydrate - a conventional cellulose solvent, the reader is referred to Pinkert et al. [12]. While it is expected that ionic liquids impart compositional changes and cleave covalent bonds of the original biomass in order to dissolve its components, little is known about the nature of these changes and how they vary with varying ionic liquids. In addition there are few accounts of full mass closures of ionic liquid pretreatments. For example Arora et al. [13] reported mass balances of [C2mim] OAc treated switchgrass $\left(160^{\circ} \mathrm{C}, 3 \mathrm{~h}, 3 \%\right.$ loading $)$ and Sun et al. [14] reported mass balances for [C2mim] OAc treatment of southern yellow pine $\left(110^{\circ} \mathrm{C}\right.$ for $16 \mathrm{~h}, 5 \%$ loading). These few accounts do not provide direct comparisons between ILs while they do not account for IL masses and do not differentiate between hemicellulose components in the recovered solids. Three most cited ionic liquids for biomass pretreatment are the imidazoliums: 1-butyl-3-methylimidazolium chloride or $[\mathrm{C} 4 \mathrm{mim}] \mathrm{Cl}, 1$ ethyl-3-methylimidazolium chloride or $[\mathrm{C} 2 \mathrm{mim}] \mathrm{Cl}$ and 1-ethyl-3-methylimidazolium acetate or [C2mim]OAc. This study a) investigates the structural and compositional characteristics of sugarcane bagasse pretreated with each of the aforementioned ionic liquids and b) provides full mass balances for these pretreatment processes.

\section{Results and discussion}

\section{Dissolution of bagasse in ILs}

The dissolution of bagasse in the three ILs under identical conditions $\left(150^{\circ} \mathrm{C}, 90 \mathrm{~min}\right.$ and $5 \%$ mass bagasse in IL, conditions as in previous work [10]) was investigated and the results are shown in Table 1 . It has to be noted that the $[\mathrm{C} 2 \mathrm{mim}] \mathrm{OAc}$ dissolution at this loading $(5 \%$ mass) was very viscous and hard to stir.

The effect of cation size is exhibited when comparing $[\mathrm{C} 4 \mathrm{mim}] \mathrm{Cl}$ with $[\mathrm{C} 2 \mathrm{mim}] \mathrm{Cl}$. In agreement with the literature [12], the smaller [C2mim] cation imparts higher dissolution (85\% cf 63\%) and this may be due to the enhanced penetration of the smaller solvent molecule resulting in higher dissolution. The effect of anion is studied by comparing $[\mathrm{C} 2 \mathrm{mim}] \mathrm{Cl}$ to $[\mathrm{C} 2 \mathrm{mim}] \mathrm{OAc}$. The acetate anion seems to favour dissolution as opposed to

Table 1 Effect of ionic liquid choice on bagasse dissolution

\begin{tabular}{|c|c|c|c|c|c|c|}
\hline \multirow[t]{2}{*}{ IL } & \multirow{2}{*}{$\begin{array}{l}\frac{\mathrm{mg}}{\text { Starting }} \\
\text { mass }\end{array}$} & \multicolumn{4}{|c|}{$\%$ starting mass } & \multirow{2}{*}{$\begin{array}{l}\text { Mass fraction } \\
\text { Unrecovered/ } \\
\text { total dissolved }\end{array}$} \\
\hline & & $\begin{array}{l}\text { Undissolved } \\
\text { solids }\end{array}$ & $\begin{array}{l}\text { Dissolved-and-recovered } \\
\text { solids }\end{array}$ & $\begin{array}{l}\text { Dissolved } \\
\text { unrecovered }\end{array}$ & $\begin{array}{l}\text { Total } \\
\text { dissolved }\end{array}$ & \\
\hline$[\mathrm{C} 4 \mathrm{mim}] \mathrm{Cl}$ & 224 & 37 & 43 & 21 & 63 & 0.33 \\
\hline$[\mathrm{C} 2 \mathrm{mim}] \mathrm{Cl}$ & 224 & 15 & 26 & 60 & 85 & 0.70 \\
\hline [C2mim] $\mathrm{OAc}$ & 224 & 4 & 56 & 40 & 96 & 0.42 \\
\hline
\end{tabular}


losses. Moreover, losses may be exacerbated due to the fact that dissolution (96\%) is well into the last recalcitrant bagasse fraction. It is probable that by reducing the severity of the treatment conditions, the ratio of dissolution to losses will be improved. Acetate has a higher hydrogen bond basicity than chloride [15] and thus its ability to disrupt hydrogen bonds and dissolve cellulose is higher. This positive correlation between the hydrogen bond basicity ( $\beta$, a Kamler-Taft solvation parameter) of the IL anion and the IL's ability to dissolve cellulose or lignocellulose is reported in the literature [15]. The superior dissolving capacity of $[\mathrm{C} 2 \mathrm{mim}] \mathrm{OAc}$ has also been reported by Sun et al. [14] who measured 93.5\% dissolution extent of southern yellow pine in [C2mim]OAc and only $26 \%$ in $[\mathrm{C} 4 \mathrm{mim}] \mathrm{Cl}$ under the same conditions (particle size $0.25-0.50 \mathrm{~mm}, 5 \%$ mass loading, $110^{\circ} \mathrm{C}$ for $16 \mathrm{~h}$ ).

\section{Fractional precipitation by stepwise addition of water}

The potential of using incremental amounts of water to fractionally precipitate IL-dissolved bagasse was tested on three ILs and the mass balances of each process determined. The fractional precipitation process was designed to yield a polysaccharide-rich and a lignin-rich fraction using two incremental additions of water (and acidification to $\mathrm{pH} \leq 1.0$ and a third addition of water to precipitate remaining dissolved material).

The first water addition used for partial precipitation of dissolved solids resulted to a water : IL mass ratio of 0.5. Preliminary qualitative studies based on visual observations of fractional precipitation with water (where bagasse soda lignin -prepared in house- and Avicel were used) indicated that this water amount should precipitate all cellulose and keep lignin in solution for water-[C4mim] $\mathrm{Cl}$ mixtures and possibly also for water[C2mim]OAc mixtures. It was also indicated that lignin precipitation was complete at a water: $[\mathrm{C} 4 \mathrm{mim}] \mathrm{Cl}$ mass ratio of 2.0. However native bagasse lignin dissolved in IL is likely to have different properties to lignin extracted with aqueous $\mathrm{NaOH}$ and then dissolved in IL. Maximum lignin recovery was ensured by acidification to a $\mathrm{pH} \leq 1.0$ and the addition of a further $1.5 \mathrm{IL}$ mass equivalents of water. Water-[C2mim] $\mathrm{Cl}$ solutions are assumed to behave in a similar manner to water-[C4mim]Cl solutions.

Bagasse pretreatments with $[\mathrm{C} 4 \mathrm{mim}] \mathrm{Cl},[\mathrm{C} 2 \mathrm{mim}] \mathrm{Cl}$ and $[\mathrm{C} 2 \mathrm{mim}] \mathrm{OAc}$ under identical conditions $(35 \mathrm{~min}$ at $150^{\circ} \mathrm{C}, 5 \%$ bagasse in IL $(2.5 \%$ for $\left.[\mathrm{C} 2 \mathrm{mim}] \mathrm{OAc})\right)$ imparted partial dissolution and the polysaccharide rich solid fractions (SF1) were recovered using water addition (water : IL mass ratio of 0.5). These conditions are deliberately less severe than in the first dissolution experiments, so as to lessen the degradation reactions and allow for the recovery of sufficient SF1 solid mass for mass balance and further analysis. The SF1 solids were washed and freeze-dried prior to analysis and enzyme saccharification. Bagasse was extracted with water and ethanol prior to treatment since better mass balance closures are obtained by removing non-structural molecules which can interfere with characterisation of solid and liquid fractions.

\section{Compositional analysis}

The composition of SF1 fractions from each IL pretreatment (at $150^{\circ} \mathrm{C}$ for $35 \mathrm{~min}$ with $25 \mathrm{~min}$ temperature ramp) are shown in Table 2. These solids contain both the undissolved bagasse and the dissolved-then-precipitated bagasse and the proportion of each has not been measured. However they have been measured $\left(\right.$ at $150^{\circ} \mathrm{C}$ for $90 \mathrm{~min}$, see Table 1). Of course the extents of biomass dissolution and degradation to material not recovered in the solid fraction ("losses" to liquid fraction) would both be expected to increase with temperature and treatment time.

In the mass balance experiments reported in Table 2, the extent of dissolution has been estimated indirectly from the solids "losses" (and ratios of dissolved mass to losses derived from Table 1$)$. For the $[\mathrm{C} 4 \mathrm{mim}] \mathrm{Cl}$ dissolution a ratio of unrecovered to total dissolved mass of 1:3 was observed (Table 1). This ratio was found to be 1:2.3 for extracted bagasse. The "losses" incurred for [C4mim $] \mathrm{Cl}$ are ca. $10 \%$ mass (Table 2), thus the dissolution extent in these experiments for $[\mathrm{C} 4 \mathrm{mim}] \mathrm{Cl}$ is estimated to be around 23\% mass. The other two ILs are known to effect different ratios of dissolution extents to losses (Table 1), and the losses incurred in these ILs

Table 2 Compositional analysis of SF1 solids from pretreatment of ethanol-extracted bagasse with three different ILs

\begin{tabular}{|c|c|c|c|c|c|c|c|c|c|c|c|}
\hline \multirow[t]{3}{*}{ Sample } & \multicolumn{9}{|c|}{$\%$ dry mass } & \multicolumn{2}{|c|}{ Ratios } \\
\hline & \multirow[t]{2}{*}{ Mass recovery } & \multirow{2}{*}{$\frac{\text { Ash }}{ \pm 0.4}$} & \multirow{2}{*}{$\frac{\mathrm{AIL}}{ \pm 0.4}$} & \multirow{2}{*}{$\frac{A S L}{ \pm 0.1}$} & \multirow[t]{2}{*}{ Total lignin } & \multirow{2}{*}{$\frac{\text { Glucan }}{ \pm 0.2}$} & \multirow{2}{*}{$\frac{\text { Xylan }}{ \pm 0.5}$} & \multirow{2}{*}{$\frac{\text { Arabinan }}{ \pm 0.08}$} & \multirow{2}{*}{$\frac{\text { Acetyl }}{ \pm 0.05}$} & \multirow[t]{2}{*}{ Arabinan /Xylan } & \multirow[t]{2}{*}{ Acetyl /Xylan } \\
\hline & & & & & & & & & & & \\
\hline Untreated (extracted) & 100 & 3.1 & 20.8 & 5.4 & 26.2 & 44.9 & 22.2 & 1.50 & 3.11 & 0.07 & 0.14 \\
\hline$[C 4 \mathrm{mim}] \mathrm{Cl}$ & 90 & 3.5 & 20.8 & 5.4 & 26.1 & 47.6 & 20.5 & 1.06 & 2.96 & 0.05 & 0.14 \\
\hline$[\mathrm{C} 2 \mathrm{mim}] \mathrm{Cl}$ & 48 & 6.1 & 25.0 & 3.8 & 28.7 & 53.4 & 11.0 & 0.60 & 1.75 & 0.05 & 0.16 \\
\hline$[\mathrm{C} 2 \mathrm{mim}] \mathrm{OAc}$ & 66 & 5.7 & 9.9 & 6.0 & 15.8 & 68.2 & 13.3 & 1.58 & 1.42 & 0.12 & 0.11 \\
\hline
\end{tabular}

AIL: Acid insoluble lignin, ASL: Acid Soluble Lignin. 
(34\% - 52\%, Table 2) suggest that the dissolutions are close to complete. These estimates were confirmed visually; it was observed that $[\mathrm{C} 4 \mathrm{mim}] \mathrm{Cl}$ contained a very large amount of undissolved fibre, [C2mim]OAc only a small amount and [C2mim] Cl almost none.

For [C4mim]Cl-treated solids, the compositional changes are small with a slight cellulose enrichment. This is primarily because only ca. $23 \%$ of the bagasse dissolved. For $[\mathrm{C} 2 \mathrm{mim}] \mathrm{Cl}$ the $\mathrm{SF} 1$ is rich in cellulose and lignin and low in hemicellulose saccharides. Given the fact that $[\mathrm{C} 2 \mathrm{mim}] \mathrm{Cl}$ dissolves and degrades bagasse components faster than $[\mathrm{C} 4 \mathrm{mim}] \mathrm{Cl}$, it is not surprising that the $[\mathrm{C} 2 \mathrm{mim}] \mathrm{Cl}$ solids are low in hemicellulose components. The [C2mim]OAc SF1 is rich in cellulose and arabinose and it is low in lignin, xylan and acetyl content. The $[\mathrm{C} 2 \mathrm{mim}] \mathrm{Cl} \mathrm{SF} 1$ is also rich in cellulose but also rich in lignin. Hemicellulose appears to have been substantially removed by $[\mathrm{C} 2 \mathrm{mim}] \mathrm{Cl}$ treatment.

It is tempting to speculate that the acetate IL and chloride ILs cleave different bonds. It appears that the acetate IL effects preferential delignification and deacetylation whereas the chloride ILs effect preferential removal of arabinose and xylan. In terms of solids composition the acetate IL appears to effect a similar outcome to aqueous alkali treatment while the chloride ILs produce a similar outcome to dilute acid treatments. This is a key finding. Note that the aqueous acid and alkali treatments involve biomass dissolution and decomposition while IL treatments involve dissolution decomposition and precipitation. Thus, the chemical processes involved are different, but the gross compositional changes are similar.

The acetate may be expected to be basic and be more reactive than chloride because acetate is a stronger base than chloride (acetic acid pKa $=4.75 c f . \mathrm{HCl} \mathrm{pKa}=-7.0$ ) but these chemical behaviours do not necessarily hold true for non-aqueous IL solutions.

Mass recovery of bagasse components after pretreatment Mass balances for bagasse components after the first water addition (water:IL mass ratio of 0.5 , yielding SF1 and LF1) of the three IL pretreatments ([C2mim]OAc, $[\mathrm{C} 4 \mathrm{mim}] \mathrm{Cl},[\mathrm{C} 2 \mathrm{mim}] \mathrm{Cl})$ were determined and are shown in Table 3.

The composition of the SF1 solids and the LF1 liquids (sum of monosaccharides and oligosaccharides) were determined. The total mass accounted for by the mass

Table 3 Mass balance of bulk biomass and of biomass components from three treatments with different ILs

\begin{tabular}{|c|c|c|c|c|c|c|c|c|c|}
\hline Dry mass (mg) & Bulk biomass & Ash & Lignin (AIL + ASL) & Glucan & Xylan & Arabinan & Acetyl & HMF & Furfural \\
\hline \multicolumn{10}{|l|}{$[\mathrm{C} 4 \mathrm{mim}] \mathrm{Cl}$} \\
\hline Untreated & 1461 & 46 & 383 & 656 & 324 & 22 & 46 & $\mathrm{n} / \mathrm{a}$ & $\mathrm{n} / \mathrm{a}$ \\
\hline SF1 & 1318 & 47 & 344 & 627 & 270 & 14 & 39 & $\mathrm{n} / \mathrm{a}$ & $\mathrm{n} / \mathrm{a}$ \\
\hline LF1 & 92 & $n / d$ & $0.4^{*}$ & 16 & 60 & 10 & 7 & 0.6 & 1.2 \\
\hline LF1 oligo & & & & 13 & 58 & 2 & 6 & & \\
\hline Total mass recovered & 1411 & 47 & 344 & 636 & 317 & 24 & 46 & & \\
\hline \multicolumn{10}{|l|}{$[\mathrm{C} 2 \mathrm{mim}] \mathrm{Cl}$} \\
\hline Untreated & 1346 & 42 & 353 & 605 & 299 & 20 & 42 & $\mathrm{n} / \mathrm{a}$ & $\mathrm{n} / \mathrm{a}$ \\
\hline SF1 & 643 & 39 & 185 & 343 & 71 & 4 & 11 & $\mathrm{n} / \mathrm{a}$ & $\mathrm{n} / \mathrm{a}$ \\
\hline LF1 & 446 & $\mathrm{n} / \mathrm{d}$ & $3^{*}$ & 188 & 214 & 14 & 28 & 1.2 & 1.4 \\
\hline LF1 oligo & & & & 175 & 204 & 3 & 27 & & \\
\hline Total mass recovered & 1089 & 39 & 188 & 516 & 267 & 20 & 39 & & \\
\hline \multicolumn{10}{|l|}{$[\mathrm{C} 2 \mathrm{mim}] \mathrm{OAc}$} \\
\hline Untreated & 699 & 22 & 183 & 314 & 155 & 10 & 22 & $\mathrm{n} / \mathrm{a}$ & $\mathrm{n} / \mathrm{a}$ \\
\hline SF1 & 463 & 26 & 73 & 316 & 62 & 7 & 7 & $\mathrm{n} / \mathrm{a}$ & $\mathrm{n} / \mathrm{a}$ \\
\hline LF1 & 88 & $\mathrm{n} / \mathrm{d}$ & $17^{*}$ & 1 & 85 & 5 & $n / d$ & 1.1 & 1.8 \\
\hline LF1 oligo & & & & $\mathrm{bdl}$ & 83 & 5 & $n / d$ & & \\
\hline Total mass recovered & 551 & 26 & 90 & 316 & 125 & 12 & 7 & & \\
\hline
\end{tabular}

Masses (average of duplicates).

Masses expressed on dry basis. Glucan is considered equal to cellulose, HMF (Hydroxymethyl furfural) is expressed as glucan equivalents and furfural as xylan equivalents, SF1: solid fraction 1, recovered from the first water addition (water:IL mass ratio $=0.5$ ), LF1: liquid fraction 1, recovered from the first water addition (water:IL mass ratio $=0.5$ ), LF1 oligo: oligosaccharides in LF1, n/d: not determined, n/a: not applicable, bdl: barely detectable.

The estimates of standard deviation (absolute, based on duplicate IL pretreatments, $3 \mathrm{df}$ ) of the recovery (and analysis) of these components (as\%mass starting component) in SF1 are $2 \%$ for glucan, $2 \%$ for xylan, 3\% for arabinan, $1 \%$ for acetyl and 2\% for lignin (acid soluble + acid insoluble). In LF1, these estimates of standard deviation for the oligosaccharides are $1 \%$ for glucan, $2 \%$ for xylan, $18 \%$ for arabinan and $3 \%$ for acetyl and for the monosaccharides they are $0.2 \%$ for glucan, $0.2 \%$ for xylan, $15 \%$ for arabinan and $0.7 \%$ for acetyl. The unacceptably high standard deviation for arabinan is attributed to its very low concentrations in the liquid fractions. *This mass does not represent all the lignin mass in the LF1 but only the recoverable lignin mass in the sum of SF2 and SF3 precipitates. 
balance determination protocol differs greatly between ILs. For $[\mathrm{C} 4 \mathrm{mim}] \mathrm{Cl}$ the original bagasse mass accounted for is $97 \%$ mass (1411 $\mathrm{mg}$ out of $1461 \mathrm{mg}$ ) and this may be attributed to the low dissolution extent achieved by this treatment. For $[\mathrm{C} 2 \mathrm{mim}] \mathrm{Cl}$, the mass recovery is $81 \%$ mass (1089 $\mathrm{mg}$ out of $1346 \mathrm{mg}$ ) and for [C2mim]OAc $79 \%$ mass (551 mg out of $699 \mathrm{mg}$ ). For all $3 \mathrm{IL}$ treatments, the remaining bagasse mass (not accounted for by mass balance determinations) is mainly (more than half) lignin that was not recoverable from the liquid fraction followed by polysaccharides (glucan followed by xylan for the chloride ILs and xylan only for [C2mim] $\mathrm{OAc})$. Note that in the liquid fraction of the [C2mim] OAc pretreatment, the biomass-derived acetyl content (representing ca. 3\% of starting bagasse mass) is not detectable since the IL counter ion is acetate.

The percent mass of each starting bagasse component in each pretreatment fraction (viz. solid fraction, liquid fraction oligosaccharides and liquid fraction monosaccharides) is listed in Table 3. Note that the degradation products HMF and furfural represent a small fraction of the mass in the liquid fraction and are included in the mass balances listed in Table 3. as glucan and xylan equivalents.

For $[\mathrm{C} 4 \mathrm{mim}] \mathrm{Cl}, 95 \%$ mass of the starting cellulose, $83 \%$ of xylan and $90 \%$ of lignin are recovered in the solid fraction. Out of the $10 \%$ lignin in the liquid fraction, only $0.3 \%$ was recoverable (see Table 4 ), indicating that the vast majority of the lignin mass remaining in the liquid fraction after addition of $0.5 \mathrm{IL}$ mass equivalents of water is in a form that cannot be recovered by further additions of water or acidification (i.e. it is soluble and likely low molecular weight material). Hemicellulose components are depolymerised preferentially while a big part of the arabinose (36\%) is removed, all of which is in

Table 4 Mass recovery and lignin content of solids recovered from the liquid fraction after treatment with three ILs

\begin{tabular}{|c|c|c|c|c|}
\hline & $\mathrm{mg}$ & $\%$ mass & $\begin{array}{l}\text { mg (\% starting } \\
\text { mass of lignin) }\end{array}$ & \\
\hline Sample & $\begin{array}{l}\text { Recovered } \\
\text { mass }\end{array}$ & $\begin{array}{l}\text { Lignin } \\
\text { content }\end{array}$ & $\begin{array}{l}\text { Lignin } \\
\text { recovery }\end{array}$ & $\mathrm{pH}$ \\
\hline [C4mim]Cl SF2 & 1.2 & 31 & $0.4(0.3)$ & 6.1 \\
\hline$[\mathrm{C} 4 \mathrm{mim}] \mathrm{Cl} \mathrm{SF} 3$ & 0.3 & $n / d$ & $n / d$ & 1.0 \\
\hline [C4mim]Cl TOTAL & 1.5 & & $0.4(\mathbf{0 . 3})$ & \\
\hline$[\mathrm{C} 2 \mathrm{mim}] \mathrm{Cl} \mathrm{SF} 2$ & 10.8 & 30 & $3.2(1.5)$ & 3.6 \\
\hline$[\mathrm{C} 2 \mathrm{mim}] \mathrm{Cl} \mathrm{SF} 3$ & 0.3 & $n / d$ & $n / d$ & 0.3 \\
\hline [C2mim]Cl TOTAL & 11.1 & & $3.2(\mathbf{1 . 5})$ & \\
\hline [C2mim]OAc SF2 & 58.2 & 23 & $13.4(9.9)$ & 7.0 \\
\hline [C2mim]OAc SF3 & 12.2 & 26 & $3.2(1.7)$ & 1.0 \\
\hline [C2mim])OAc TOTAL & 70.4 & & $16.6(\mathbf{1 1 . 7})$ & \\
\hline
\end{tabular}

Masses expressed on dry basis. the monomeric form. The arabinofuranosyl glycosidic linkages are acid labile and consequently arabinose loss is a characteristic of acid treatments [5]. The fact that arabinose is found in the monomeric form indicates either that the arabinosyl groups removed are terminal or if they are not, that the ester bonding of arabinose to lignin is concomitantly cleaved.

Mass balance analysis for $[\mathrm{C} 2 \mathrm{mim}] \mathrm{Cl}$ treatment reveals the same trends as for $[\mathrm{C} 4 \mathrm{mim}] \mathrm{Cl}$ but since dissolution is near complete in this IL the trends are more pronounced. Lignin and cellulose are the predominant components of the recovered solids reflecting the relative thermal and chemical stability of these polymers in solution when compared to hemicelluloses. Out of $78 \%$ mass arabinan in the liquid fraction, $55 \%$ mass is in monomeric form. Out of $50 \%$ lignin expected in the liquid fraction only $1.5 \%$ is recoverable.

Preferential hemicellulose removal resulting in lignin and cellulose enrichment of the treated solids is also a characteristic of dilute acid treatments. The chloride imidazolium ILs appear to remove arabinose preferentially. Note that in previous work [10], where the undissolved fraction of bagasse after $[\mathrm{C} 4 \mathrm{mim}] \mathrm{Cl}$ dissolution was analysed, it was shown that cellulose dissolved to a greater extent than hemicelluloses (the effect of dissolution only). The analysis of SF1 here indicates that hemicellulose is preferentially removed (the net effect of dissolution and reprecipitation). Cellulose is preferentially dissolved but at a high $D P$ (degree of polymerisation) and mostly recovered by precipitation with the addition of water, whereas the little hemicellulose that dissolves, depolymerises and becomes soluble in the water-IL mixture (i.e. does not reprecipitate).

The mass distributions of bagasse components after $[\mathrm{C} 2 \mathrm{mim}] \mathrm{OAc}$ pretreatment are also shown in Table 3. While $100 \%$ mass of the original cellulose is recovered in the solid fraction the lignin content is reduced to $40 \%$ mass. Cellulose appears to get solubilised in a high $D P$ form since it is all precipitated with the addition of water and none of it is found in the aqueous liquid fraction. These features indicate that $[\mathrm{C} 2 \mathrm{mim}] \mathrm{OAc}$ affords excellent cellulose preservation and substantial delignification. However, out of the $60 \%$ mass lignin extracted in the liquid fraction, only $11.7 \%$ was recoverable. Since arabinose content is comparatively high in the solid fraction and found in the oligomeric liquid fraction only, it can be concluded that arabinose is preserved and that no terminal arabinosyl groups have been removed (i.e. the arabinosyl glycosidic linkages in hemicellulose are stable in $[\mathrm{C} 2 \mathrm{mim}] \mathrm{OAc})$. Finally the acetate content of the solid fraction is reduced by $70 \%$ mass indicating substantial deacetylation.

The arabinan recovery is inflated (115\% mass) and this is attributed to the large standard deviation of 
arabinose measurements in the liquid fraction as discussed earlier.

Overall the $[\mathrm{C} 2 \mathrm{mim}] \mathrm{OAc}$ pretreatment affords distinctly different compositional changes to the chloride IL pretreatments. These distinct differences are delignification, deacetylation preservation of cellulose glycosidic bonds (as deduced from the absence of cellulose mass in the liquid fraction) and preservation of arabinosyl groups in hemicellulose. These differences are similar to the differences between acid and alkali aqueous pretreatments. Note that previous work by Fu et al. [16], where triticale straw was treated with six different ILs, is in agreement with the present study in that $[\mathrm{C} 2 \mathrm{mim}] \mathrm{OAc}$ affords extensive delignification while preserving the cellulose fraction of the treated biomass.

\section{ATR-FTIR}

The SF1 from each IL was also analysed using ATRFTIR and the spectra are shown in Figure 1. Table 5 lists the assignments of the absorption bands of interest. In general, these spectra reflect the compositional characteristics discussed above. For example it is clearly discernible that the band absorbances which are characteristic of lignin are relatively low in the spectrum of SF1 treated with [C2mim]OAc when compared to other spectra.

Infrared spectra were also used to estimate crystallinity of each SF1. The absorbance at $1421 \mathrm{~cm}^{-1}$ is viewed as typical of crystalline regions of cellulose and the absorption band at $893 \mathrm{~cm}^{-1}$ typical of amorphous regions; the ratio of these two bands represents a crystallinity index
Table 5 Assignments of FTIR-ATR absorption bands for bagasse

\begin{tabular}{|c|c|}
\hline $\begin{array}{l}\text { Band position } \\
\left(\mathrm{cm}^{-1}\right)\end{array}$ & Assignment \\
\hline 1730 & $\begin{array}{c}\mathrm{C}=\mathrm{O} \text { stretching vibration in acetyl groups of } \\
\text { hemicelluloses }\end{array}$ \\
\hline 1600 & $C=C$ stretching vibration in aromatic ring of lignin \\
\hline 1510 & $\mathrm{C}=\mathrm{C}$ stretching vibration in aromatic ring of lignin \\
\hline 1421 & $\mathrm{CH}_{2}$ scissoring at $\mathrm{C}(6)$ in cellulose \\
\hline 1368 & Symmetric $\mathrm{C}-\mathrm{H}$ bending in cellulose \\
\hline 1236 & $\begin{array}{l}\text { C-O stretching vibration in lignin, xylan and ester } \\
\text { groups }\end{array}$ \\
\hline 1100 & $\begin{array}{l}\text { O-H association band in cellulose and hemicelluloses } \\
\text { (associated with crystalline cellulose) }\end{array}$ \\
\hline 1030 & C-O stretching vibration in cellulose and hemicelluloses \\
\hline 974 & $\begin{array}{c}\text { C-O stretching vibration in arabinosyl side chains in } \\
\text { hemicellulose }\end{array}$ \\
\hline 895 & Glucose ring stretch, $\mathrm{C} 1-\mathrm{H}$ deformation \\
\hline
\end{tabular}
[17-20].

(CrI) also known as lateral order index [17]. The crystallinity indices of the solids recovered from all three IL treatments $(0.19$ for $[\mathrm{C} 2 \mathrm{mim}] \mathrm{OAc}, 0.21$ for $[\mathrm{C} 4 \mathrm{mim}] \mathrm{Cl}$ and 0.37 for $[\mathrm{C} 2 \mathrm{mim}] \mathrm{Cl}$ ) were significantly lower that of the untreated bagasse solids (0.88). Decrystalisation of cellulose is a known and unique effect of IL pretreatments [10]. The estimate of the standard deviation (absolute) for this crystallinity index-measurement is 0.02 (based on duplicate IL pretreatments, $3 \mathrm{df}$ ). These indices combined with the observed shift of the $1034 \mathrm{~cm}^{-1}$ band to lower wavenumber, represent a significant loss

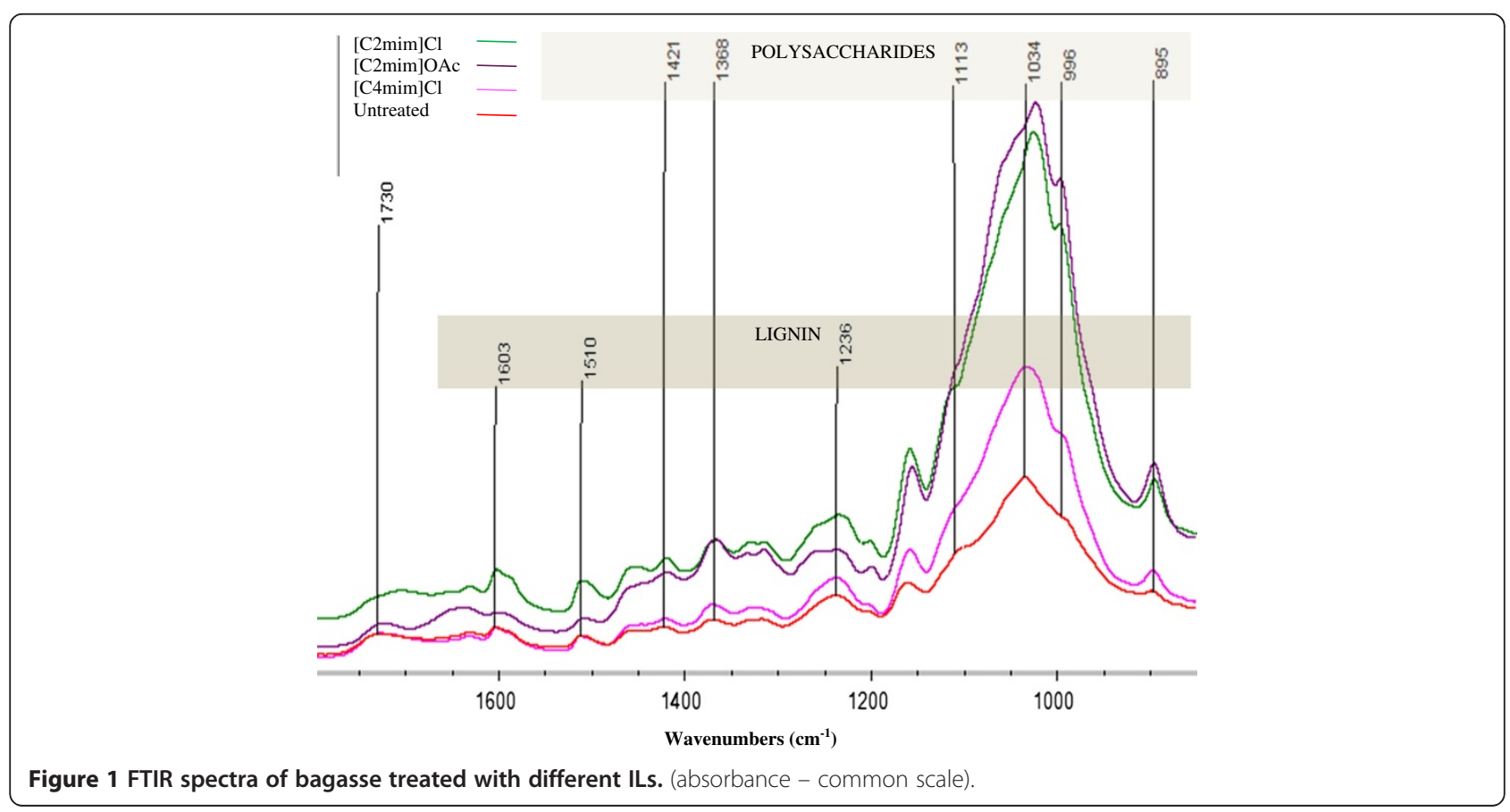


of crystallinity of cellulose after treatment in all three ILs. Note that despite only ca. $23 \%$ dissolution of bagasse in $[\mathrm{C} 4 \mathrm{mim}] \mathrm{Cl}$ the $\mathrm{SF} 1 \mathrm{CrI}$ is significantly lower than starting bagasse. As shown in previous work by the authors, the cellulose in the IL-undissolved fraction can also undergo decrystallisation [10].

\section{Enzyme saccharification}

The progress of saccharification resulting from each IL treatment for cellulose and hemicellulose (as xylan) was monitored and is plotted in Figure 2. Initial rates of cellulose saccharification are very fast for all IL treatments, and this is the effect of cellulose decrystallisation which is common to all three treatments. The extent of saccharification is higher for the $[\mathrm{C} 2 \mathrm{mim}]^{+}$ILs than for the

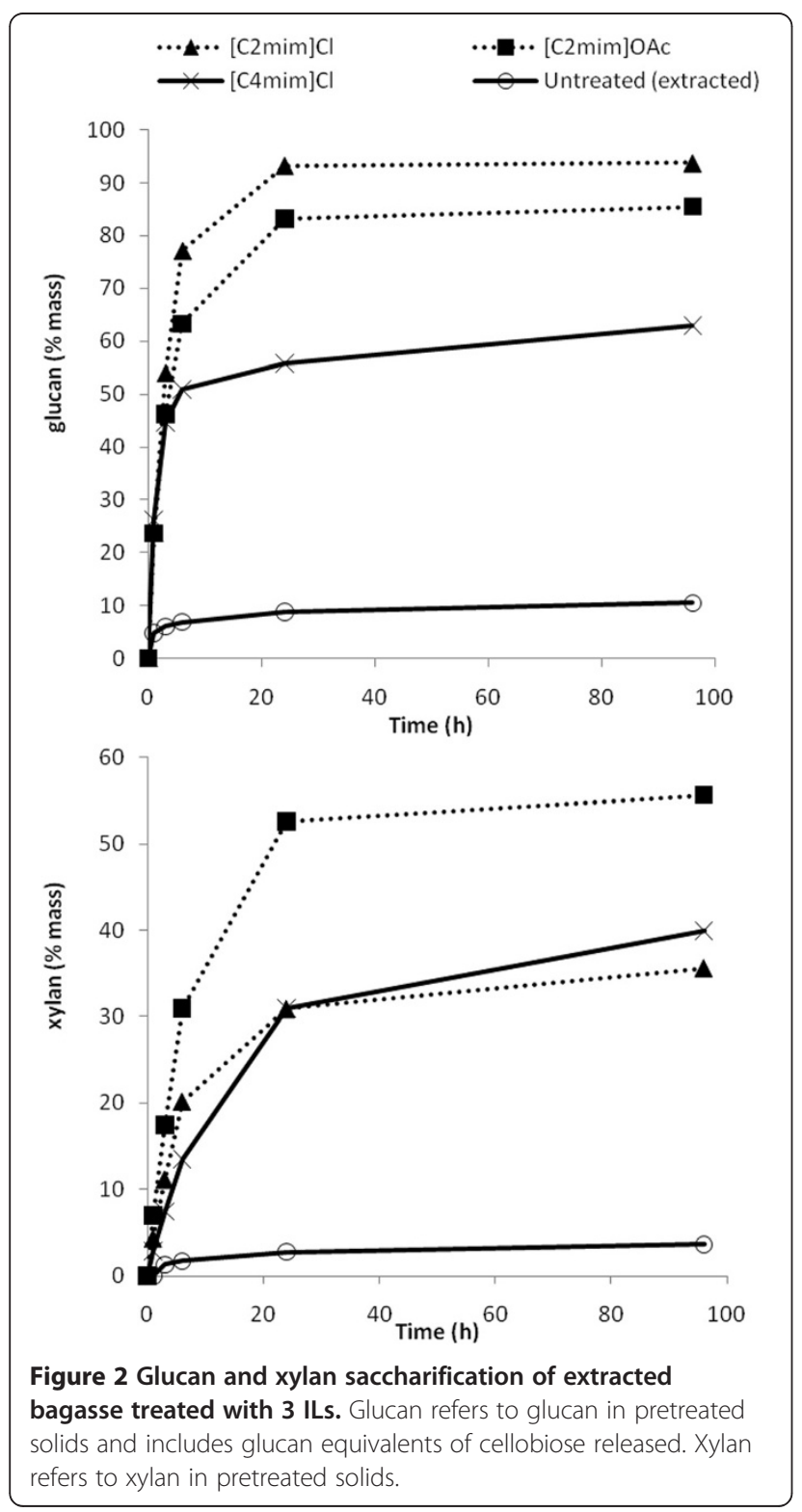

$[\mathrm{C} 4 \mathrm{mim}]^{+} \mathrm{IL}$ and of the $[\mathrm{C} 2 \mathrm{mim}]^{+}$salts, the chloride anion gives a higher saccharification yield. Given that [C2mim]OAc delignifies as well as decrystallises bagasse, it is surprising that $[\mathrm{C} 2 \mathrm{mim}] \mathrm{Cl}$ yielded a higher final saccharification. This is possibly due to the different ligninhemicellulose bonds (as identified by compositional and infrared analysis and discussed above) that survive in the solids after these two pretreatments. The fast initial saccharification rates resulting from $[\mathrm{C} 4 \mathrm{mim}] \mathrm{Cl}$ treatment reflect the presence of structural changes while the low final saccharification yields are a consequence of a lower extent of dissolution and indicate the absence of compositional and covalent bonding perturbation in the undissolved solids.

Interestingly, the hemicellulose saccharification of [C2mim]OAc treated bagasse proceeds faster and closer to completion than for the other two ILs. This shows that the delignification achieved by [C2mim]OAc results in improved hemicellulose saccharification results, while for the chloride IL treated solids the hemicellulose is not as accessible to enzymes due to the persistence of lignin. It is likely that covalent linkages between lignin and hemicelluloses survive chloride IL treatment and limit the extent of saccharification of hemicelluloses.

The cellulose and hemicellulose saccharification extents achieved by each IL at $24 \mathrm{~h}$, as $\%$ mass theoretical in the starting bagasse (prior to pretreatment), are shown in Figure 3. Factoring in both the saccharification extent and the recovery of the starting polysaccharide mass in the pretreated solids, [C2mim]OAc affords the highest cellulose conversion due to a combination of rapid saccharification and no degradation of cellulose upon pretreatment. $[\mathrm{C} 2 \mathrm{mim}] \mathrm{Cl}$ and $[\mathrm{C} 4 \mathrm{mim}] \mathrm{Cl}$ have

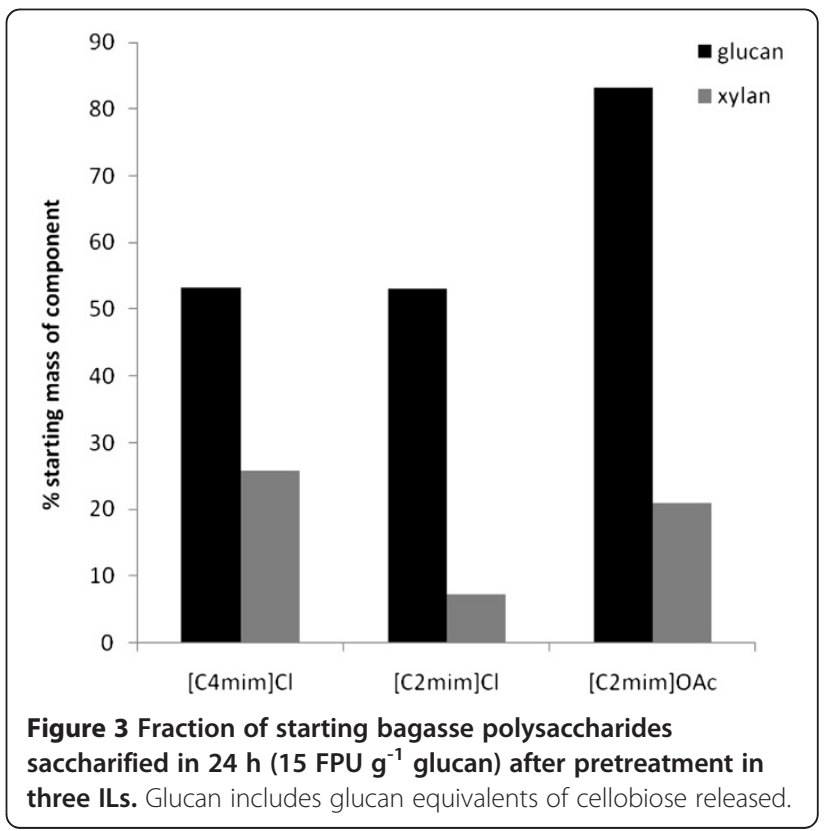


similar theoretical cellulose conversions. The much higher dissolution extent in $[\mathrm{C} 2 \mathrm{mim}] \mathrm{Cl}$ did not benefit the overall performance of this pretreatment since losses in $[\mathrm{C} 2 \mathrm{mim}] \mathrm{Cl}$ were much higher than in $[\mathrm{C} 4 \mathrm{mim}] \mathrm{Cl}$. In terms of hemicellulose saccharification yield, $[\mathrm{C} 4 \mathrm{mim}] \mathrm{Cl}$ performs best mainly because more hemicellulose is preserved in polymeric and recoverable form.

In general and in agreement with the literature, for the cations, it appears that the shorter alkyl chain of $[\mathrm{C} 2 \mathrm{mim}] \mathrm{Cl}(c f .[\mathrm{C} 4 \mathrm{mim}] \mathrm{Cl})$ imparted faster dissolution and greater extent of saccharification. However higher dissolution rates were accompanied by higher degradation rates. The anion effect is greater since it imparts entirely distinct dissolution patterns. In the case of acetate compared to chloride, the acetate ion appears to impart a more alkali-resembling effect while the chloride ones a more acid-resembling effect.

\section{Lignin recovery}

The second addition of water to the liquid fractions of the three IL pretreatments to a water:IL mass ratio of 2.0 yielded solid fractions (SF2).. Acidification of the liquid fractions and a third water addition yielded some additional precipitate (SF3).. For all SF2 and SF3 samples, lignin content was measured by the acetyl bromide method and FTIR spectra were obtained. SF2 and SF3 lignin contents and recovered masses are reported in Table 4. The weight of all liquid fraction precipitates and their lignin content was used to determine the total amount of lignin recoverable from the liquid fraction of each IL pretreatment. The lignin recovery from the liquid fraction of all three IL pretreatments was low $(0.3 \%$ to $11.7 \%$ mass of starting lignin).
The ATR-FTIR spectra for the solids precipitated from each IL pretreatment from the 3.5 mass ratio water addition (SF3) are shown in Figure 4. Spectra of SF2 precipitates were also obtained but were not different to those of the SF 3 precipitates. These spectra have intense absorbances at the hemicellulose characteristic bands between $1175 \mathrm{~cm}^{-1}$ and $1000 \mathrm{~cm}^{-1}$. This indicates that the majority of the non-lignin component of these fractions (ca. $70 \%$ mass) is comprised of hemicellulose. This is in agreement with previous discussion demonstrating the preservation of lignin-hemicellulose bonding upon biomass dissolution in ILs. The $[\mathrm{C} 2 \mathrm{mim}] \mathrm{OAc}$ precipitate in particular has a strong characteristic band at $974 \mathrm{~cm}^{-1}$ indicative of arabinosyl groups. This again is in agreement with previous discussion supporting preservation of covalent bonds to arabinosyl moieties during [C2mim]OAc dissolution whilst they are labile in chloride IL dissolutions.

Undoubtedly, a large proportion of the dissolved lignin remains in the water-IL mixture even after addition of more water (3.5 water : IL mass ratio) and lowering of the $\mathrm{pH}$ to $\leq 1.0$. In this fractional precipitation approach there are difficulties in quantitatively recovering lignin since only a small fraction of it precipitates. Furthermore the precipitate is far from pure lignin as it can contain up to $70 \%$ mass hemicellulose. While the cellulose fraction can be obtained in an enriched and extensively decrystallised form, the poor lignin recovery and coprecipitation of hemicelluloses argues against the use of this approach in an industrial setting.

\section{Ionic liquid recovery}

The recovery of the ionic liquid solvent forms part of the mass balance closure and it was measured using ion

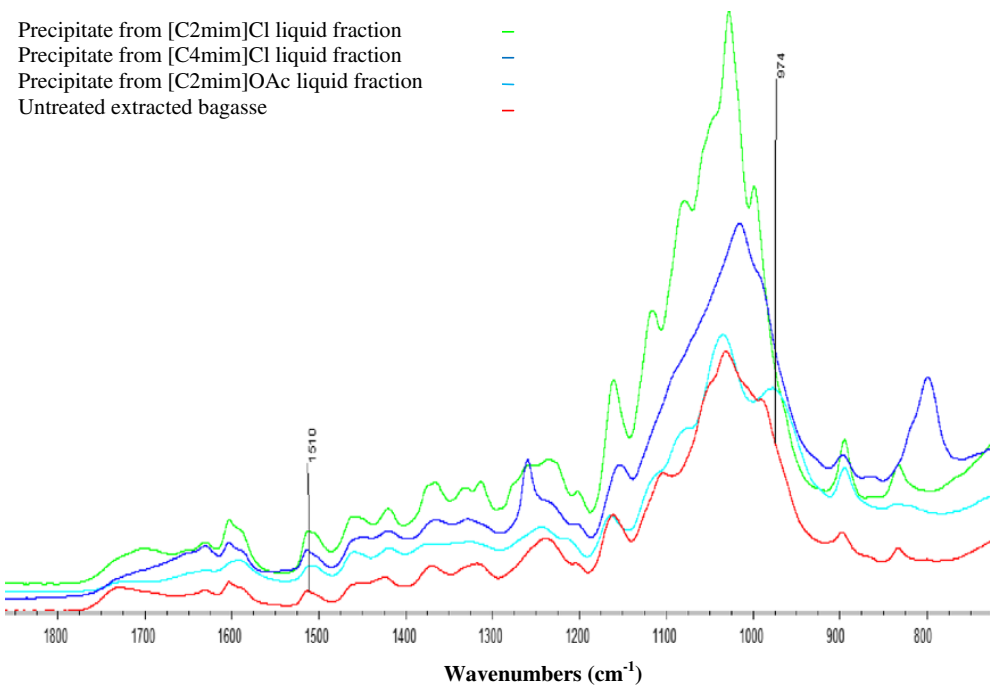

Figure 4 FTIR spectra of precipitate recovered after precipitation in 3.5 water : IL mass ratio (acidified to $\mathrm{pH} \leq 1$ ) in three ILs. (absorbance - common scale). 
chromatography of the liquid fraction of each pretreatment. The recovery of all ions appears to be full $(100 \%$ mass) within experimental error. The standard deviation of repeat analyses was $2 \%$. At least under laboratory conditions and scale little or no degradation of IL occurs and the IL could be completely recovered. Covalent bonding of acetate ions from [C2mim]OAc to biomass [21] and the reaction of imidazole cations with saccharides to form imidazole glycosides [22] may occur but at the low biomass concentrations used here the magnitudes of these reactions are small by comparison to the experimental error in the measurement of $\mathrm{IL}$ recovery.

\section{Conclusions}

Mass balances are reported for pretreatment of bagasse with $[\mathrm{C} 4 \mathrm{mim}] \mathrm{Cl},[\mathrm{C} 2 \mathrm{mim}] \mathrm{Cl}$ and $[\mathrm{C} 2 \mathrm{mim}] \mathrm{OAc}$. The acetate IL preferentially removes lignin and acetyl, while it preserves arabinosyl groups, resembling the effects of aqueous alkali pretreatments. Chloride ILs impart an opposite effect and resemble dilute acid pretreatments. The shorter IL alkyl chain accelerated the dissolution, pretreatment and degradation. Regulated addition of water-antisolvent affected a polysaccharide rich precipitate by maintaining dissolved lignin in all three ILs. In terms of saccharification yields, material recovery and delignification, [C2mim]OAc ranks as the most suitable IL for biomass pretreatment. The mass of all ILs used was fully recovered. Future work should focus on elucidating the mechanisms of lignocellulose dissolution and depolymerisation in acetate and chloride-based ILs. In addition the distinct chemistries of these IL solvents might be used to development an understanding of the reactions involved in other solvent based biomass pretreatments.

\section{Methods \\ Bagasse}

Sugarcane bagasse (Rocky Point sugar mill, Pimpama, Queensland) comprising long cuticle fibres and core pith particles (mostly ca. $5 \mathrm{~mm}$ to $50 \mathrm{~mm}$ ) was air dried for a week on metal trays then size reduced (to $<10 \mathrm{~mm}$ ) with a knife mill before being mixed and subsampled by the cone and split method and stored at $4{ }^{\circ} \mathrm{C}$. Before use the bagasse was ground (to $<2 \mathrm{~mm}$ ) using an electric lab mill (Retsch SM100, Haan, Germany). The material was ground for ca. $1 \mathrm{~min}$ per batch to avoid excess heating, placed on top of two brass sieves $(0.5 \mathrm{~mm}$ and $0.25 \mathrm{~mm}$ ) and in a sieve shaker for $20 \mathrm{~min}$, and the fraction collected between the two sieves was used as the starting material. Moisture content was measured gravimetrically (convection oven, $105^{\circ} \mathrm{C}$, overnight) before every use and was $10 \pm 1 \%$ mass except where otherwise indicated.

\section{Chemicals}

The ionic liquids (1-butyl-3-methylimidazolium chloride $[\mathrm{C} 4 \mathrm{mim}] \mathrm{Cl}(\geq 95 \%)$ melting point as per MSDS (m.p.) $73^{\circ} \mathrm{C}$, 1-ethyl-3-methylimidazolium chloride $[\mathrm{C} 2 \mathrm{mim}] \mathrm{Cl}$ ( $\geq 95 \%)$ m.p. $80^{\circ} \mathrm{C}$, and 1-ethyl-3-methylimidazolium acetate $[\mathrm{C} 2 \mathrm{mim}] \mathrm{OAc}(\geq 90 \%)$ m.p. $-20^{\circ} \mathrm{C}$, SigmaAldrich, NSW) were all dried in a vacuum oven (at $80^{\circ} \mathrm{C}$ $-90^{\circ} \mathrm{C}$, ca. $4 \mathrm{~mm} \mathrm{Hg},>12 \mathrm{~h}$ ) prior to use. Initial moisture content (at the time of weighing the IL for each use) was typically ca. $2 \%$ of total mass for [C4mmim] Cl and $1 \%$ for $[\mathrm{C} 2 \mathrm{mim}] \mathrm{Cl}$ and $[\mathrm{C} 2 \mathrm{mmim}] \mathrm{OAc}$ as measured by Karl Fischer titration. At this point it is worth noting that although the m.p. of neat $[\mathrm{C} 4 \mathrm{mim}] \mathrm{Cl}$ is $73^{\circ} \mathrm{C}$ (as per the MSDS provided by the manufacturer), its $2 \%$ moisture content was sufficient to maintain it in liquid phase at room temperature. Cellulose (Avicel PH-101), dimethyl sulphoxide (DMSO) (99.9\%) and Karl Fischer HYDRANAL titrant 2E and solvent $\mathrm{E}$ were purchased from Sigma-Aldrich (Sydney, NSW). Cellulase / $\beta$ glucosidase mixture (Accelerase 1000) was purchased from Genencor (Danisco A/S, Denmark). Water was Millipore-filtered and deionised (Milli-Q-plus) to a specific resistivity of $18.2 \mu \mathrm{S}$ at $25^{\circ} \mathrm{C}$. All other solvents and chemicals were analytical grade.

\section{Bagasse soda lignin preparation}

Bagasse soda lignin was prepared by soda pulping of bagasse $\left(175^{\circ} \mathrm{C}, 2 \mathrm{~h}\right.$, bagasse $10 \%$ mass, $\mathrm{NaOH} 10 \%$ mass $)$ and precipitating the resulting black liquor with acid ( $2 \mathrm{M} \mathrm{H}_{2} \mathrm{SO}_{4}$ ) add to reduce the $\mathrm{pH}$ to 3.0. The precipitate was then redissolved in aqueous $\mathrm{NaOH}$ (10\% mass) and reprecipitated by addition of acid to reduce the $\mathrm{pH}$ to 3.0. The recovered lignin solids were washed and dried $\left(40^{\circ} \mathrm{C}\right.$, vacuum oven).

\section{Karl Fischer titration}

A Karl Fischer automated titrator (Radiometer Copenhagen TIM 900) with ethanol based HYDRANAL reagents was used to measure moisture content of ILs after drying and prior to use.

\section{Preliminary dissolution experiments}

Non-extracted bagasse was treated in $[\mathrm{C} 4 \mathrm{mim}] \mathrm{Cl}$, $[\mathrm{C} 2 \mathrm{mim}] \mathrm{Cl},[\mathrm{C} 2 \mathrm{mim}] \mathrm{OAc}$ under conditions used in previously reported work [10] $\left(150^{\circ} \mathrm{C}, 90 \mathrm{~min}\right.$ and $5 \%$ mass bagasse in IL). The treated mixture (partially dissolved bagasse in IL) was then diluted with DMSO and the undissolved and the dissolved-then-precipitated (with water) solid fractions were recovered, dried and weighed as described in previous work by the authors [10]. The estimates of standard deviation (absolute) for this technique (based on duplicate dissolution experiments, 5 degrees of freedom, (df)) are $6 \%$ starting mass for 
undissolved solids and 3\% starting mass for dissolvedthen-precipitated solids.

\section{Mass balance determinations for three IL treatments}

Bagasse $(0.25 \mathrm{~mm}-0.5 \mathrm{~mm})$ was extracted with ethanol and water using a Sohxlet device according to the NREL protocol for biomass extractives [23]. ILs (ca. $30 \mathrm{~g}$ of either $[\mathrm{C} 4 \mathrm{mim}] \mathrm{Cl}$ or $[\mathrm{C} 2 \mathrm{mim}] \mathrm{Cl}$ or $[\mathrm{C} 2 \mathrm{mim}] \mathrm{OAc}$ in duplicate) were weighed in sealable pressure glass tubes (ACE glass $50 \mathrm{~mL}$ ). At this point, IL (ca. $0.5 \mathrm{~g}$ ) was weighed and set aside for IL recovery analysis (using ion chromatography). Extracted bagasse (3.5\% moisture) (ca. $1.5 \mathrm{~g}$ for $[\mathrm{C} 4 \mathrm{mim}] \mathrm{Cl}$ and $[\mathrm{C} 2 \mathrm{mim}] \mathrm{Cl}$ and $0.75 \mathrm{~g}$ for $[\mathrm{C} 2 \mathrm{mim}] \mathrm{OAc}$ ) was added to each pressure tube, sealed with Teflon stoppers and placed in an oil bath which was stabilised at $150^{\circ} \mathrm{C}$ with magnetic stirring at $200 \mathrm{rpm}$. Sealing the tubes prevented volatile losses such as acetic acid (b.p. $118.1^{\circ} \mathrm{C}$ ) or furfural (b.p. $161.7^{\circ} \mathrm{C}$ ) from the degradation of xylose. The tubes were left in the oil bath for $60 \mathrm{~min}$ ( $25 \mathrm{~min}$ of which at temperature ramp and $35 \mathrm{~min}$ at $150^{\circ} \mathrm{C}$ ) and, upon removal, placed in an ice bath with magnetic stirring. After $2 \mathrm{~min}$, the tubes were removed from the ice bath and water was added equal to 0.5 mass fraction of the originally added IL. The tube was sealed again and agitated vigorously until a homogenous solution between water and IL appeared to form. The contents of each tube were quantitatively transferred into a preweighed polypropylene centrifuge tube and centrifuged at $10000 \times \mathrm{g}$ for $20 \mathrm{~min}$. The liquid contents of the centrifuge tube were decanted to a new preweighed polypropylene centrifuge tube and weighed (liquid fraction 1 or LF1). The pellet (SF1) was centrifuge washed with distilled water $(5 \times 30 \mathrm{~mL}$ at $10000 \times \mathrm{g}$ and $5 \mathrm{~min}-10 \mathrm{~min}$ cycles), freeze dried overnight $\left(-85^{\circ} \mathrm{C}, 80 \mathrm{mT}\right)$ and weighed. LF1 1 was precipitated with additional water resulting to a water : IL mass ratio of 2.0. Precipitation and coagulation of solids was aided by storing at $4^{\circ} \mathrm{C}$ overnight followed by shaker incubating at $55^{\circ} \mathrm{C}-70^{\circ} \mathrm{C}$ for $60 \mathrm{~min}$. The resulting precipitate (solid fraction 2 or SF2) was centrifuge washed, freeze dried and weighed. The resulting liquid was acidified to $\mathrm{pH} \leq 1$ and mixed with a further $1.5 \mathrm{IL}$ mass equivalents of water to maximise precipitation of lignin in solution. This final precipitate (solid fraction 3 or SF3) was centrifuge washed, freeze dried and weighed.

Losses of liquid components to washings of pellets were accounted for by weighing pellets prior to washing and after drying (it is assumed that the composition of these lost liquid components is the same as the bulk liquid). Similarly, subsampling for analysis was accounted for by careful attention to mass changes.

SF1 and the starting biomass were characterised using the NREL acid hydrolysis protocol [23]. Solid fractions 2 and 3 were characterised for lignin content with the acetyl bromide protocol described by Iiyama and Wallis [24]. The sample of LF1 was directly injected onto the HPLC and the Ion Chromatograph (IC) for quantification of monosaccharides and IL ions respectively while the soluble oligosaccharides were determined by acid hydrolysis. All methods are described in detail in the following sections. The distribution of cellulose, hemicellulose and lignin between solid fractions, liquid fraction monosaccharides and liquid fraction oligosaccharides was finally reported as\% mass of the components in the starting material (Table 3). The estimates of standard deviation (absolute, based on duplicate IL pretreatments, $3 \mathrm{df}$ ) of the recovery (and analysis) of these components (as\%mass starting component) in SF1 are $2 \%$ for glucan, $2 \%$ for xylan, $3 \%$ for arabinan, $1 \%$ for acetyl and $2 \%$ for lignin (acid soluble + acid insoluble). In LF1, these estimates of standard deviation for the oligosaccharides are $1 \%$ for glucan, $2 \%$ for xylan, $18 \%$ for arabinan and $3 \%$ for acetyl and for the monosaccharides they are $0.2 \%$ for glucan, $0.2 \%$ for xylan, $15 \%$ for arabinan and $0.7 \%$ for acetyl. The unacceptably high standard deviation for arabinan is attributed to its very low concentrations in the liquid fractions.

\section{Compositional analysis of "solid fraction 1"}

Compositional analysis of SF1 samples was carried out using the standard NREL procedure for determination of structural carbohydrates and lignin in biomass [25]. All samples were freeze dried overnight prior to analysis. Each sample $(250 \mathrm{mg})$ was treated with $\mathrm{H}_{2} \mathrm{SO}_{4}$ (72\% mass) at $30^{\circ} \mathrm{C}$ for $1 \mathrm{~h}$. These samples and a sugar recovery standard (SRS, containing known concentrations of glucose, xylose and arabinose) were then exposed to dilute $\mathrm{H}_{2} \mathrm{SO}_{4}(4 \%)$ at $121^{\circ} \mathrm{C}$ for $1 \mathrm{~h}$. The hydrolysis products were determined by HPLC (Waters) equipped with a RI detector (Waters 410) and a Bio-Rad HPX$87 \mathrm{H}$ column operated at $85^{\circ} \mathrm{C}$. The mobile phase consisted of $5 \mathrm{mM} \mathrm{H}_{2} \mathrm{SO}_{4}$ with a flow rate of $0.6 \mathrm{~mL} \mathrm{~min}^{-1}$. The glucose, xylose and arabinose results were corrected for acid decomposition using the\% mass recovery from the SRS. The polysaccharide and acetyl mass content were calculated by conversion of the monosaccharide and acetic acid results with appropriate multiplication factors ( 0.90 for glucose, 0.88 for xylose and arabinose, 0.683 for acetic acid). In bagasse, glucan content is considered equal to cellulose content since there is no glucose in the hemicelluloses of sugarcane and sucrose has been removed previously at the sugar mill. The acid- insoluble lignin (AIL) after acid hydrolysis was measured as the mass loss of insoluble residue at $575^{\circ} \mathrm{C}$. The acidsoluble lignin (ASL) was measured by UV-vis spectrophotometer (Cintra 40) at $240 \mathrm{~nm}$ with an extinction coefficient value of $25 \mathrm{~L} \mathrm{~g} \mathrm{~g}^{-1} \mathrm{~cm}^{-1}$ [25]. Ash was determined by placing separate sample fractions at $575^{\circ} \mathrm{C}$. 


\section{Compositional analysis of monosaccharides in liquid fraction 1}

Each sample of LF1 $(0.5 \mathrm{~mL})$ was weighed in $1.5 \mathrm{~mL}$ Eppendorf tubes and diluted with water $(0.5 \mathrm{~mL})$. The contents were vortexed thoroughly, filtered through a $0.45 \mu \mathrm{m}$ nylon filter and injected to a Waters HPLC as described earlier. Glucose, xylose, arabinose and acetic acid masses were converted to glucan, xylan, arabinan and acetate masses using appropriate multiplication factors (as listed earlier). In addition, it was assumed that the detected hydroxymethylfurfural (HMF) and furfural were products of cellulose and xylan degradation respectively. Therefore, HMF and furfural masses were converted to cellulose and xylan mass equivalents using multiplication factors of 1.28 and 1.38 respectively [23].

\section{Compositional analysis of oligosaccharides in liquid fraction 1}

Each sample of LF1 $(0.5 \mathrm{~mL})$ and SRS solution $(0.5 \mathrm{~mL})$ were weighed in $2 \mathrm{~mL}$ twist-top Eppendorf tubes, diluted with water $(1 \mathrm{~mL})$ and acidified (with $72 \%$ mass $\mathrm{H}_{2} \mathrm{SO}_{4}$ ) to a $\mathrm{pH}$ of 0.3 . The contents were vortexed thoroughly and autoclaved $\left(121^{\circ} \mathrm{C}\right.$ for $60 \mathrm{~min}$; autoclaving did not affect mass). After cooling to room temperature, the autoclaved tube contents were filtered through a $0.45 \mu \mathrm{m}$ nylon filter and injected onto the HPLC system described earlier. After SRS correction for acid decomposition of sugars and subtraction of the monosaccharide composition results, the difference was converted to polysaccharide mass equivalents (using appropriate multiplication factors as listed earlier) in order to arrive at the composition of the soluble oligosaccharides in LF1.

\section{ATR-FTIR}

A small amount of freeze dried fibre, enough to cover the surface of the probe, was placed on the diamond probe of a Thermo Nicolet 870 FTIR (software: OMNIC 7.3). The sample was pressed with an anvil to increase the surface contacting the probe. Sixty-four scans were acquired for each spectrum and the two replicate spectra for each sample were overlayed. No differences in the replicate spectra of this study were observed and thus only the first spectrum of each sample was used for analysis.

\section{Acetyl bromide for lignin quantification in solid fractions 2 and 3}

The acetyl bromide method as described by Iiyama and Wallis [24] was used to determine the\% mass lignin content of solid fractions 2 and 3. Freeze dried solids (ca. $10 \mathrm{mg}$ ) were weighed in glass tubes and acetyl bromide in acetic acid (25\% mass, $10 \mathrm{~mL}$ ) and then perchloric acid (70\% mass, $0.1 \mathrm{~mL}$ ) were added. The tubes were sealed with Teflon screw caps and placed in temperature controlled rotary shaker $\left(70^{\circ} \mathrm{C}\right.$ and $100 \mathrm{rpm}$ for $\left.30 \mathrm{~min}\right)$. After cooling to room temperature the tubes were opened and $2 \mathrm{M} \mathrm{NaOH}(10 \mathrm{~mL})$ and then glacial acetic acid $(25 \mathrm{~mL})$ were added. After agitation, absorbance (280 nm, quartz cuvettes, Cintra UV spectrometer) was measured against glacial acetic acid. The resulting solution was analysed with a Cintra-40 UV spectrometer and the absorbance was referenced to a cuvette with glacial acetic acid. Dilutions with glacial acetic acid were necessary for some samples so that the absorbance was $<1.0$. The absorbance was converted to percent mass concentration of lignin using an extinction coefficient of $25 \mathrm{~L} \cdot \mathrm{g}^{-1} \cdot \mathrm{cm}^{-1}$. The extinction coefficient was determined with the use of a calibration curve based on bagasse of known lignin content. The estimate of standard deviation (absolute) of this technique (duplicate samples of untreated bagasse and soda lignin, $4 \mathrm{df}$ ) (as\% dry mass of solid analysed) is 3 .

\section{Enzymatic saccharification of solids from 3 IL treatments}

Enzymatic hydrolysis experiments (SF1 fraction) were performed in $20 \mathrm{~mL}$ scintillation vials on a rotary shaker $\left(150 \mathrm{rpm}, 50^{\circ} \mathrm{C}\right)$ in volumes of $5 \mathrm{~mL}$ with a biomass load of $50 \mathrm{mg}$ cellulose equivalent and Accelerase 1000 (Genencor) activity of $15 \mathrm{FPU} \mathrm{g}^{-1}(25 \mu \mathrm{L}$ of Accelerase as received) in $50 \mathrm{mM}$ citrate buffer ( $\mathrm{pH}$ 4.7). Samples $(0.2 \mathrm{~mL})$ were periodically removed, placed in ice, then in boiling water ( $2 \mathrm{~min}$ ) and centrifuged. Cellobiose, glucose and xylose concentrations were measured by HPLC (HPLC system as described earlier except a Shodex SPO-810 HPLC column at $85^{\circ} \mathrm{C}$ with a mobile phase of ultrapure water at $0.6 \mathrm{~L} \mathrm{~min}^{-1}$ were used.). The glucose and cellobiose results were converted to glucan mass equivalents and xylose was converted to xylan mass equivalents using appropriate multiplication factors.

The estimates of standard deviation (absolute) of this analysis (based on duplicate IL pretreatments' saccharification extents at different time points, $18 \mathrm{df}$ ) are $2 \%$ mass of glucan and $0.9 \%$ mass of xylan.

\section{Recovery of IL}

IL set aside at the start of mass balance experiments (starting IL) was brought to a volume of $50 \mathrm{~mL}$ with deionised water. Similarly, known masses of LF1 were diluted with deionised water and injected onto the ion chromatograph (Metrohm 761 with a conductivity detector). For cation analysis, samples were injected onto a Metrosep C 2150 (150 $\mathrm{mm} \times 4 \mathrm{~mm})$ column with an aqueous mobile phase (25\% volume acetone, $6 \mathrm{mM}$ tartaric acid and $0.75 \mathrm{mM}$ dipicolinic acid) at $1 \mathrm{~mL} \mathrm{~min}^{-1}$. For anion analysis samples were injected onto a Metrosep ASupp5 $(150 \mathrm{~mm} \times 4 \mathrm{~mm})$ column with an aqueous mobile phase $\left(1 \mathrm{mM} \mathrm{NaHCO}_{3}\right.$ and $\left.3.2 \mathrm{mM} \mathrm{Na}_{2} \mathrm{CO}_{3}\right)$ at 
$0.7 \mathrm{~mL} \mathrm{~min}^{-1}$ and suppressed by post-column addition of $\mathrm{H}_{2} \mathrm{SO}_{4}(50 \mathrm{mM})$. IL mass balance was determined from the results of these analyses. The estimate of standard deviation (absolute) of this technique (as\% mass of ions in starting IL) for both cations and anions and for all 3 ILs is 2 (based on duplicate IL pretreatments, $6 \mathrm{df}$ ).

\section{Abbreviations}

IL: Ionic Liquid; [C4mim]Cl: 1-butyl-3-methylimidazolium chloride; [C2mim] $\mathrm{Cl}$ : 1-ethyl-3-methylimidazolium chloride; [C2mim]OAc: 1-ethyl-3methylimidazolium acetate.

\section{Competing interests}

The authors declare that they have no competing interests.

\section{Authors' contributions}

All work has been carried out by SK under the supervision of LE and WD. All authors read and approved the final manuscript.

\section{Acknowledgements}

Funding was generously provided by the Greek State Scholarship Foundation (IKY), the Queensland Government, and Queensland University of Technology. Bagasse soda lignin was prepared by Dylan Cronin.

\section{Author details}

'School of Chemistry, Queensland University of Technology, GPO Box 2434, Brisbane, QLD 4001, Australia. ${ }^{2}$ Sugar Research and Innovation, Queensland University of Technology, GPO Box 2434, Brisbane, QLD 4001, Australia.

Received: 16 February 2012 Accepted: 23 July 2012

Published: 24 August 2012

\section{References}

1. EIA (U.S. Energy Information Association): International Energy Outlook. 2010 http://www.eia.gov/forecasts/archive/ieo10/index.html.

2. Kumar P, Barrett DM, Delwiche MJ, Stroeve P: Methods for pretreatment of lignocellulosic biomass for efficient hydrolysis and biofuel production. Ind Eng Chem Res 2009, 48(8):3713-3729.

3. Mosier N, Wyman C, Dale B, Elander R, Lee YY, Holtzapple M, Ladisch M: Features of promising technologies for pretreatment of lignocellulosic biomass. Bioresour Technol 2005, 96(6):673-686.

4. Wyman CE, Dale BE, Elander RT, Holtzapple M, Ladisch MR, Lee YY: Coordinated development of leading biomass pretreatment technologies. Bioresour Technol 2005, 96(18):1959-1966.

5. Hamilton JK: The behaviour of wood carbohydrates in technical pulping processes. Pure App/ Chem 1962, 5(1-2):197-218.

6. El Seoud OA, Koschella A, Fidale LC, Dorn S, Heinze T: Applications of ionic liquids in carbohydrate chemistry:a window of opportunities. Biomacromolecules 2007, 8(9):2629-2647.

7. Edye LA, Doherty WOS: Fractionation of a lignocellulosic material. 2007. AU2007900603.

8. Edye LA, Doherty WOS, Blinco JA, Bullock GE: The sugarcane biorefinery: Energy crops and processes for the production of liquid fuels and renewable commodity chemicals. International Sugar Journal 2006, 108(1285):19-20. 22-27.

9. Fort DA, Remsing RC, Swatloski RP, Moyna P, Moyna G, Rogers RD: Can ionic liquids dissolve wood? Processing and analysis of lignocellulosic materials with 1-n-butyl-3-methylimidazolium chloride. Green Chem 2007, 9(1):63-69.

10. Karatzos S, Edye LA, Doherty WOS: Enhanced saccharification kinetics of sugarcane bagasse pretreated in 1-butyl-3-methylimidazolium chloride at high temperature and without complete dissolution. Bioresour Technol 2011, 102(19):9325-9329.

11. Kilpelainen I, Xie H, King A, Granstrom M, Heikkinen S, Argyropoulos DS: Dissolution of wood in ionic liquids. J Agric Food Chem 2007, 55(22):9142-9148.

12. Pinkert A, Marsh KN, Pang SS, Staiger MP: Ionic liquids and their interaction with cellulose. Chem Rev 2009, 109(12):6712-6728.
13. Arora R, Manisseri C, Li C, Ong M, Scheller H, Vogel K, Simmons B, Singh S: Monitoring and analyzing process streams towards understanding ionic liquid pretreatment of switchgrass (Panicum virgatum L.). Bioenergy Res 2010, 3(2):134-145.

14. Sun N, Mustafizur R, Qin Y, Maxim ML, Rodríguez H, Rogers RD: Complete dissolution and partial delignification of wood in the ionic liquid 1-ethyl-3-methylimidazolium acetate. Green Chem 2009, 11(5):646-655.

15. Brandt A, Hallett JP, Leak DJ, Murphy RJ, Welton T: The effect of the ionic liquid anion in the pretreatment of pine wood chips. Green Chemistry 2010, 12(4):672-679.

16. Fu D, Mazza G, Tamaki Y: Lignin extraction from straw by ionic liquids and enzymatic hydrolysis of the cellulosic residues. J Agric Food Chem 2010, 58:2915-2922

17. Široký J, Blackburn R, Bechtold T, Taylor J, White P: Attenuated total reflectance Fourier-transform infrared spectroscopy analysis of crystallinity changes in lyocell following continuous treatment with sodium hydroxide. Cellulose 2010, 17(1):103-115.

18. Labbé N, Rials TG, Kelley SS, Cheng Z-M, Kim J-Y, Li Y: FT-IR imaging and pyrolysis-molecular beam mass spectrometry: new tools to investigate wood tissues. Wood Sci Technol 2005, 39(1):61-76.

19. Pandey KK: A study of chemical structure of soft and hardwood and wood polymers by FTIR spectroscopy. J Appl Polymer Sci 1999, 71(12):1969-1975.

20. Sun JX, Sun XF, Sun RC, Su YQ: Fractional extraction and structural characterization of sugarcane bagasse hemicelluloses. Carbohydr Polym 2004, 56(2):195-204.

21. Karatzos S, Edye LA, Wellard RM: The undesirable acetylation of cellulose by the acetate ion of 1-ethyl-3-methylimidazolium acetate. Cellulose 2011, 19(1):307-312

22. Ebner G, Schiehser S, Potthast A, Rosenau T: Side reaction of cellulose with common 1-alkyl-3-methylimidazolium-based ionic liquids. Tetrahedron Lett 2008, 49:7322-7324.

23. Sluiter A, Ruiz R, Scarlata C, Sluiter J, Templeton D: Determination of extractives in biomass: National Renewable Energy Laboratory; 2008. Available online http://www.nrel.gov/biomass/pdfs/42619.pdf.

24. liyama $K$, Wallis AFA: An improved acetyl bromide procedure for determining lignin in woods and wood pulps. Wood Sci Technol 1988, 22 (3):271-280

25. Sluiter A, Hames B, Ruiz R, Scarlata C, Sluiter J, Templeton D, Crocker D: Determination of structural carbohydrates and lignin in biomass: National Renewable Energy Laboratory; 2008. Available online http://www.nrel.gov/ biomass/pdfs/42618.pdf

doi:10.1186/1754-6834-5-62

Cite this article as: Karatzos et al: Sugarcane bagasse pretreatment using three imidazolium-based ionic liquids; mass balances and enzyme kinetics. Biotechnology for Biofuels 2012 5:62.

\section{Submit your next manuscript to BioMed Central and take full advantage of:}

- Convenient online submission

- Thorough peer review

- No space constraints or color figure charges

- Immediate publication on acceptance

- Inclusion in PubMed, CAS, Scopus and Google Scholar

- Research which is freely available for redistribution 